\title{
Quality of antenatal care and pregnancy outcome in the slums of Guwahati city
}

\author{
Talukdar Rijusmeeta ${ }^{1}$, Madaan Sandeep ${ }^{2}$ \\ Received on May 02, 2019; editorial approval on June 28, 2019
}

\begin{abstract}
Background: The primary aim of antenatal care is to achieve at the end of every pregnancy healthy baby and mother. Objective: To assess the quality of antenatal care (ANC) and its relation to pregnancy outcome. Materials and methods: A community based cross-sectional study was carried out from August 2011-July 2012. Study was conducted in 7 slums in Guwahati city, Assam, selected by systematic random sampling. Total of 400 mothers who had delivered within 1 year were selected randomly and interviewed. Information about socio demographic variables, ANC services and pregnancy outcome were collected. Data were collected in a predesigned, pretested and semi-structured proforma and analyzed using statistical software. Results: Majority (81.25\%) of mothers were registered for ANC. About $61 \%$ mothers had 3 or more ANC out of which $66.25 \%$ mothers were registered within 12 weeks of pregnancy. While $81.25 \%$ mothers had their BP measured, only 25.75\% had 100 or more IFA tablets and 70\% had 2 doses of TT, 64.5\% had their $\mathrm{Hb} \%$ estimated, $74.5 \%$ were advised on proper rest and nutrition, 75\% were aware of danger signs of pregnancy. While $81.25 \%$ were informed about institutional delivery, only $55.25 \%$ mothers had institutional delivery. Association between IFA consumption by mothers and birth weight of babies was highly significant $(p<.001)$. Conclusion: Utilization of 3 or more ANC and institutional deliveries were low in the slums. Thus, awareness of benefits of quality ANC must be generated in slums to ensure increased utilization.
\end{abstract}

Keywords: Maternal health; pregnancy care; institutional delivery; birth weight.

\section{INTRODUCTION}

Globally hundreds of women and children are dying due to pregnancy related complications and low income countries are contributing a large percentage. ${ }^{1}$ As per WHO, India contributes $19 \%$ of maternal mortality globally. ${ }^{2}$ Assam is a priority state with high maternal mortality rates. Infant mortality rate has not improved much and there is a vast difference when compared with high performing states. ${ }^{3}$

Antenatal care is the 'care before birth' to promote the wellbeing of mother and fetus, and is essential to reduce maternal morbidity and mortality, low-weight births and perinatal mortality. ${ }^{4,5}$ However, the content and quality of antenatal care and the availability of effective referral and essential obstetric care are important for antenatal care to be effective. ${ }^{5}$ High quality antenatal care is seen as a fundamental right of all women to safeguard their health and that of their infants providing opportunities for risk factor intervention. ${ }^{5}$

The high maternal and infant mortality rate of Assam is an issue of concern and needs to be looked upon. National rural health mission was launched in 2005 for the rural areas, but the poor reside in slums too and whether they have access to and are they utilizing the antenatal services remains unanswered. Programmes and policies have been launched to address the problem but how well are they utilized and how effective are they? The focus of the analysis is on the maternal health care practices, to examine whether and how disadvantaged the pregnant ladies in urban slums are in aspects
Address for correspondence:
${ }^{1}$ Assistant Professor
Department of Community Medicine
Mobile: +918723930817
Email: rijusmeeta@gmail.com
${ }^{2}$ Assistant Professor (Corresponding Author)
Department of Anatomy
K.M. Medical College, Mathura, UP.
Mobile: +919896542122
Email: drsandeepmadaan84@gmail.com 
of maternal care. Considering these facts the study was conducted with the following objective, that is, to assess the quality of antenatal care and to study the association of birth weight and various components of antenatal care.

\section{MATERIALSAND METHODS}

This cross sectional study was undertaken in the slums of Guwahati city, Kamrup Metro district, Assam. The urban slums of Guwahati city is spread over 60 municipal wards covering a population of $1,67,796$ with a total of 90 slum pockets encompassing 27,966 households. ${ }^{6}$ The slum population under study is a heterogeneous mix of rural-urban migrants, irrespective of religion, language, place of origin and economic status. The study was conducted from August 2011 to July 2012.

Study population: The study population includes post natal mothers within 1 year of delivery residing in urban slums of Guwahati city.

Exclusion criteria: Women who went to their mother's house for delivery.

Sample size and sampling design: According to DLHS 3(District Level Household Survey), 45.1\% of women in Assam avail 3 or more ANC services. Sample size estimated at $5 \%$ level of significance with an absolute error of $5 \%$ is worked out as follows:

$$
\begin{aligned}
& \mathrm{n}=4 \mathrm{pq} / \mathrm{l}^{2} \\
& \text { Where, } \mathrm{n}=\text { sample size } \\
& \mathrm{p}=\text { prevalence } \\
& \mathrm{l}=\text { absolute error } \\
& \mathrm{n}=400
\end{aligned}
$$

Out of 90 slums in the city, ${ }^{6}$ the slums with less than 100 house-holds were clubbed together and considered as one unit after which the total number of slums came to be 89 .
Considering the fact that pregnant women constitute $3 \%$ of the total population ${ }^{7}$ number of pregnant women per slum is calculated to be 57 approximately. Therefore, to get a sample of 400 mothers 7 slums were visited from a total of 89 slums. The 7 slums were selected by systematic random sampling method using random number table. In each slum, house to house visits were conducted and the lactating mothers were selected randomly to get the desired number of mothers.

Data collection tools: Data were collected in a predesigned, pretested and semi-structured proforma

Data collection technique: The selected slums were visited and the respondents were carefully briefed about the purpose of the study so as to get full co-operation from them while conducting the study. House to house visits were made till 400 respondents could be found in the selected areas. Interviews were conducted at the house of the respondents. The study being a cross sectional one, only one visit was made to each individual mother.

A pre-designed, pretested, semi-structured proforma was used during the data collection. In the first part of the proforma detailed socio-demographic data were collected. In the next part of the proforma to see the utilisation of the maternal health services, data related to utilisation of antenatal, intranatal, postnatal services and regarding Janani Suraksha Yojana were collected. In the final part of the proforma, information about breast feeding and contraceptive service utilisation was included.

Data analysis: Data was structured and analysed using Microsoft excel.

\section{RESULTS}

Table 1 shows $37.5 \%$ of mothers were married at or below 19 years of age and majority of the mothers $(86.5 \%)$ were in the age group of 20-24 and 25-29 years.

Table 1 Distribution of mothers by age at marriage and their current age

\begin{tabular}{|c|c|c|c|c|c|c|}
\hline \multirow{2}{*}{$\begin{array}{c}\text { Agc at marriagc } \\
\text { (in ycars) }\end{array}$} & \multicolumn{5}{|c|}{ Current agc of mothcr (in ycars) } & \multirow{2}{*}{ Total } \\
\cline { 2 - 6 } & $<20$ & $20-24$ & $25-29$ & $30-34$ & $\geq 35$ & \\
\hline$<15$ & $6(1.5)$ & $2(0.5)$ & $2(0.5)$ & - & - & $10(2.5)$ \\
\hline $15-19$ & $14(3.5)$ & $70(17.5)$ & $45(11.25)$ & $10(2.5)$ & $1(0.25)$ & $140(35)$ \\
\hline $20-24$ & - & $113(28.25)$ & $78(19.5)$ & - & $2(0.5)$ & $193(48.25)$ \\
\hline $25-29$ & - & - & $36(9)$ & $18(4.5)$ & - & $54(13.5)$ \\
\hline$\geq 30$ & - & - & - & $3(0.75)$ & - & $3(0.75)$ \\
\hline Total & $20(5)$ & $185(46.25)$ & $161(40.25)$ & $31(7.75)$ & $3(0.75)$ & $400(100)$ \\
\hline
\end{tabular}

*parenthesis in bracket show row wise percentage.

Out of 400 women, $81.25 \%$ of mothers were registered for ANC and $18.75 \%$ mothers were not registered. As regards number of ante natal checkups and duration of pregnancy at the time of ANC registration, table 2 shows that out of 325 mothers, $75 \%$ of mothers had more than or equal to three ANC and $6.8 \%$ of mothers had only 1 ANC. Majority, $81.54 \%$ 
of mothers were registered for ANC before 12 weeks of 28 weeks of pregnancy. pregnancy and $1.84 \%$ mothers were registered for ANC after

Table 2 Distribution of mothers by the number of ante natal checkups and duration of pregnancy at the time of ANC registration

\begin{tabular}{|c|c|c|c|c|c|}
\hline \multirow[t]{2}{*}{ No. of ANC } & \multicolumn{5}{|c|}{ Duration of pregnancy } \\
\hline & $<12$ weeks & $12-16$ weeks & $16-28$ weeks & $>28$ weeks & Total \\
\hline 1 & $\begin{array}{c}6 \\
(1.85)\end{array}$ & $\begin{array}{c}1 \\
(0.3)\end{array}$ & $\begin{array}{c}11 \\
(3.38)\end{array}$ & $\begin{array}{c}4 \\
(1.23)\end{array}$ & $\begin{array}{c}22 \\
(6.8)\end{array}$ \\
\hline 2 & $\begin{array}{c}33 \\
(10.15)\end{array}$ & $\begin{array}{c}23 \\
(7.1)\end{array}$ & $\begin{array}{c}1 \\
(0.3)\end{array}$ & $\begin{array}{c}2 \\
(0.6)\end{array}$ & $\begin{array}{c}59 \\
(18.2)\end{array}$ \\
\hline$\geq 3$ & $\begin{array}{c}226 \\
(69.5)\end{array}$ & $\begin{array}{c}17 \\
(5.23)\end{array}$ & $\begin{array}{c}1 \\
(0.3)\end{array}$ & - & $\begin{array}{l}244 \\
(75)\end{array}$ \\
\hline Total & $\begin{array}{c}265 \\
(81.54)\end{array}$ & $\begin{array}{c}41 \\
(12.62)\end{array}$ & $\begin{array}{l}13 \\
(4)\end{array}$ & $\begin{array}{c}6 \\
(1.84)\end{array}$ & $\begin{array}{c}325 \\
(100)\end{array}$ \\
\hline
\end{tabular}

Table 3 shows that out of the 325 mothers registered for ANC, $100 \%$ mothers had their BP and weight measured and also had their abdominal examination done, $92.3 \%$ of mothers took TT injection and $91.7 \%$ of mothers consumed IFA tablets. Regarding health education \& advice received by mothers, $74.5 \%$ of mothers were advised on proper nutrition, $75 \%$ of mothers were advised on danger signs of pregnancy and
$81.25 \%$ of mothers were told about the expected date of delivery and about institutional delivery. $80.3 \%$ mothers had done $\mathrm{ABO}$ grouping and Rh typing, $79.4 \%$ of mothers had their blood tested for $\mathrm{Hb} \%$ and $33.23 \%$ of mothers underwent USG during their last pregnancy. Out of the total $400,48 \%$ of deliveries took place in Government hospital, $44.75 \%$ were home deliveries and $7.25 \%$ deliveries were in a private hospital.

Table 3 Distribution of mothers an as per the categories to assess quality of antenatal care

\begin{tabular}{|c|c|c|c|}
\hline Variable & Yes & No & Total \\
\hline Consumption of IFA & 298(91.7\%) & $27(8.31 \%)$ & $325(100 \%)$ \\
\hline Receipt of TT & $300(92.3 \%)$ & $25(7.69 \%)$ & $325(100 \%)$ \\
\hline $\mathrm{BP}$ and $\mathrm{Wt}$ taken & $325(100 \%)$ & - & $325(100 \%)$ \\
\hline Abdominal examination done & $325(100 \%)$ & - & $325(100 \%)$ \\
\hline Advise on proper nutrition & $298(74.5 \%)$ & $102(25.5 \%)$ & $400(100 \%)$ \\
\hline Advise on danger signs of pregnancy & $300(75 \%)$ & $100(25 \%)$ & $400(100 \%)$ \\
\hline Told about expected date of delivery & $325(81.25 \%)$ & $75(18.75 \%)$ & $400(100 \%)$ \\
\hline Advise on institutional delivery & $325(81.25 \%)$ & $75(18.75 \%)$ & $400(100 \%)$ \\
\hline $\mathrm{Hb} \%$ done & $258(79.38 \%)$ & $67(20.61 \%)$ & $325(100 \%)$ \\
\hline $\mathrm{ABO}$ and $\mathrm{Rh}$ grouping done & $261(80.3 \%)$ & $64(19.69 \%)$ & $325(100 \%)$ \\
\hline Urine examination done & $259(79.69 \%)$ & $66(20.3 \%)$ & $325(100 \%)$ \\
\hline Ultrasonography done & $108(33.23 \%)$ & $217(66.77 \%)$ & $325(100 \%)$ \\
\hline Hospital delivery & $221(55.25 \%)$ & $179(44.75 \%)$ & $400(100 \%)$ \\
\hline
\end{tabular}


Table 4 Distribution of mothers by intake of IFA tablets and birth weight of baby

\begin{tabular}{|c|c|c|c|c|c|c|c|}
\hline \multirow{2}{*}{$\begin{array}{c}\text { IFA } \\
\text { consumption }\end{array}$} & \multicolumn{5}{|c|}{ Birth weight of baby } & \multirow[t]{2}{*}{ Weight not taken } & \multirow[t]{2}{*}{ Total } \\
\hline & & $<2000 \mathrm{~g}$ & $\begin{array}{l}(2000) \\
2499) \mathrm{g}\end{array}$ & $\geq 2500 \mathrm{gg}$ & T'otal & & \\
\hline \multirow[t]{2}{*}{ Yes } & No. & 4 & 52 & 113 & $169(56.7)$ & \multirow[t]{2}{*}{$129(43.3 \%)$} & \multirow{2}{*}{$\begin{array}{c}298 \\
(100)\end{array}$} \\
\hline & $\%$ & $2.1 \%$ & $30.8 \%$ & $66.9 \%$ & $100 \%$ & & \\
\hline \multirow[t]{2}{*}{ No } & No. & 8 & 42 & 2 & $52(50.98)$ & \multirow[t]{2}{*}{$50(49.02)$} & \multirow{2}{*}{$\begin{array}{c}102 \\
(100)\end{array}$} \\
\hline & $\%$ & $15.4 \%$ & $80.8 \%$ & $3.8 \%$ & $100 \%$ & & \\
\hline \multirow[t]{2}{*}{ Total } & No. & 12 & 94 & 115 & $221(55.25)$ & \multirow[t]{2}{*}{$179(44.75)$} & \multirow{2}{*}{$\begin{array}{c}400 \\
(100)\end{array}$} \\
\hline & $\%$ & $5.4 \%$ & $42.5 \%$ & $52 \%$ & $100 \%$ & & \\
\hline
\end{tabular}

\section{DISCUSSION}

The present study was carried out in 89 slums of Guwahati. 400 women who had delivered within last 1 year were interviewed and analysis was done for their ANC service utilization and its subsequent outcome during delivery.

\section{Comparative analysis:}

The findings of different parameters in the present study have been analyzed comparatively with other studies as follows:

The current study shows that significant number of participants (37.5\%) got married before 19 years of age. As per Coverage Evaluation Survey Report Assam (2008-09) majority of the mothers surveyed $(57.6 \%)$ were married at the age of 15-19 years. In AHS (2010-11) it is stated that, percentage of currently married women, aged 20-24 years, married before legal age of 18 years in Kamrup urban is $33.4 \%$. These results corroborate the findings of the current study. To combat the hazards of early marriage and pregnancy awareness should be spread among slum dwellers regarding complications of teenage pregnancies.

Out of 400 women who participated in this study, 325 $(81.25 \%)$ were registered for ANC. Utilization of individual ANC services was done by all the registered women. Advice on proper nutrition $(74.5 \%)$, advice on danger signs of pregnancy $(75 \%)$, and information about the expected date of delivery and about institutional delivery $(81.25 \%)$, ABO grouping and $\mathrm{Rh}$ typing (80.3\%), blood test for $\mathrm{Hb} \%$ (79.4\%) and USG during their last pregnancy (33.23\%) were the other ANC services provided to them. The findings of the study are almost similar and are in accordance with the findings of CES Assam (2009) ${ }^{8}$ and AHS (2010-11). ${ }^{9}$ CES Assam (2009) reveals that $67.8 \%$ of the total mothers received health education in respect of proper nutrition during pregnancy, $71.9 \%$ received delivery advice $\& 72.5 \%$ were told the expected date of delivery. On the other hand, only about $52 \%$ of the total mothers were told about signs of pregnancy.

According to AHS (2010-11), percentage of mothers whose blood was examined for $\mathrm{Hb}$ estimation for Kamrup district of Assam was 63\% and for Kamrup (urban) it was 70.5\%. Data of Kamrup district shows, an ultrasound test was performed for $39.8 \%$ of pregnancies.
Out of the total $400,48 \%$ of deliveries took place in Government hospital, $44.75 \%$ were home deliveries and $7.25 \%$ deliveries were in a private hospital. In a study conducted byRRC-NE, ${ }^{10}$ showed that $66 \%$ of the total deliveries were conducted in govt. hospitals and other govt. facilities like PHC / CHC etc. whereas 7\% deliveries were conducted in private health facilities like private hospitals, maternity homes etc.

Findings of the present study regarding utilization of individual ANC services like TT injection (92.3\%) and IFA consumption $(91.7 \%)$ were found to be more than DLHS $3(2007-2008)^{11}$ which reported consumption of 100 IFA tablets by $36.9 \%$ mothers in Assam. P.K. Mony et al (2001) $)^{12}$ in their study in slums of Vellore town, Southern India found that complete dose of TT was taken by $94.1 \%$ mothers.

Out of 400 mothers, $55.25 \%$ mothers had their babies weight taken and $44.75 \%$ did not have their babies weight taken. Significant statistical association was found between IFA consumption by mothers, ANC check up, advice on proper nutrition and the birth weight of babies. The results of study done by Nisha et al $(2014)^{13}$ corroborate the findings of the current study.

\section{CONCLUSION}

The present study shows that there is a need to generate awareness among the slum dwellers to prevent marriage of girls below 18 years of age and to prevent child bearing among young women.This can be done with the help of health workers by conducting regular home visits. They should also motivate the mothers for antenatal checkups. The health workers should inform mothers about the benefits of safe motherhood practices and institutional delivery.

Conflict of interest: None declared.

Ethical clearance: Taken.

Source of funding: None declared.

Author Disclosure: (1) The article is original with the author(s) and does not infringe any copyright or violate any other right of any third party. (2) The article has not been published (whole or in part) elsewhere, and is not being considered for publication elsewhere in any form, except as provided herein. (3) All author(s) have contributed sufficiently in the article to take public responsibility for it and (4) all 
author(s) have reviewed the final version of the above manuscript and approved it for publication.

Acknowledgement: This study has been sponsored by Department of Biotechnology, Ministry of Science \& Technology, DBT nodal cell, Tezpur University, Tezpur.

\section{REFERENCES}

1. World Health Organization. The world health report: make every mother and child count. [online] 2005 [cited Aug 2013]; Available from: URL:http://www.who.int/ whr/2005/en/

2. World Health Organisation [Online]. 2012 [cited August 2013]; Available from: URL:https://www.who.int/gho/ maternal_health/countries/ind.pdf

3. Sample registration system. Special bulletin on maternal mortality in India. Office of the Registrar General, India, Ministry of Home Affairs, Govt. of India 2013.

4. World Health Organization. Antenatal care: report of a technical working group. Geneva: 31 Oct- 4 Nov 1994. p. 121-2.

5. Purisch SE, Gyamfi BC. Epidemiology of preterm birth. Clinic Oste Gyneco 2008;31:521-32.

6. Guwahati Development Department, Government of Assam, February, 2009.

7. Handbook for Vaccine \& Cold Chain Handlers. 2nd ed.
Ministry of Health \& Family Welfare, Government of India. India; 2016. p. 121.

8. Coverage evaluation survey report Assam. Regional Resource Centre for Northeastern States, Ministry of Health and Family Welfare, Government of India. 200809. p. 53-5.

9. Annual Health Survey Factsheet. Office of the Registrar General \& Census Commissioner, India Ministry of Home Affairs, GOI. Assam; 2010-11. p. 99.

10. Ministry of Health and Family Welfare, Government of India. Regional Resource Centre for North eastern States [Online]. 2013 [cited August 2013]; Available from: URL:http://www.rrcnes.gov.in/spip_appriasal.html

11. District level household and facility survey (DLHS-3), 2007-08: India. International Institute for Population Sciences (IIPS). Mumbai; 2010. p. 53-81.

12. Mony PK, Verghese L, Bhattacharji S, George A, Thoppuram P, Mathai M. Demography, environmental status and maternal health care in slums of Vellore town, Southern India. IJCM 2006;31(4):230-3.

13. Malhotra Nisha, Upadhyay RP, Bhilwar Meenakshi, Choy Nicholas, Green Timothy. The role of maternal diet and Iron-folic acid supplements in influencing birth weight: evidence from India's national family health survey. J of Tropical Pediatrics 2014;60(6):454-60. 
